\title{
Why are Certain Accents Judged the Way they are? Decoding Qualitative Patterns of Accent Bias
}

Amee P. Shah*

School of Health Sciences, Stockton University, United States

Corresponding Author: Amee P. Shah, E-mail: amee.shah@stockton.edu

\section{ARTICLE INFO}

Article history

Received: February 13, 2019

Accepted: May 11, 2019

Published: June 30, 2019

Volume: 10 Issue: 3

Advance access: May 2019

Conflicts of interest: None

Funding: None

\author{
Key words: \\ Accent, \\ Stereotypes, \\ Listener Bias, \\ Accent Ratings, \\ Listener Judgment, \\ Qualitative Judgments, \\ Accent Modification
}

\begin{abstract}
While it is well-established that listeners judge accents different from their own, and that this listener bias has pervasive consequences to the speakers, we have only offered a cursory attention to understand the nature of this accent bias. This paper explores listeners' judgments, ratings, and qualitative comments associated with psychosocial, personality and behavioral attributes of seven accents. Fifty-five respondents evaluated six different attributes of seven regional and foreign accents on a Likert scale. Means, Standard Deviations, and statistical significance of the difference in the respondent ratings from the Midwestern standard were computed, as well as qualitative analyses of the judgments were conducted. Results showed that perceptual biases for many attributes of the regional and foreign accents were significant at the $95 \%$ level. Results also showed that the accent recognition was consistent across a group of people from the same region, and the identification of the region of the accent was largely accurate. Qualitative analyses revealed that the underlying bases of listener judgments are typically borne out of the influence of media, TV, and movies. Besides character traits, the listeners also frequently inferred occupations/professions from the accents. Accent judgments are not reserved for foreign accents alone; regional accents are also subject to judgments and stereotypes. Findings provide important insights for clinicians and teachers working in the area of accent interventions, specifically in improving understanding about how listeners judge accents and how those messages need to be addressed in developing awareness and empowerment for clients in accent interventions. Other implications in the field of speech language pathology, education, social science, communication and business are also discussed.
\end{abstract}

\section{INTRODUCTION}

Speakers with different first language (L1s) speaking English, or those from different geographical regions have discernible foreign or regional accents that determine their regional, geographical, linguistic, and/or ethnic identity. Depending on their own language and regional background, listeners have been found infer speakers' traits based on their preconceived judgments and opinions of those accents, for example judging the speakers on attributes of intelligence, competence, attractiveness, trustworthiness and so on (see comprehensive review in Giles \& Coupland, 1991); The impact of these listener biases and judgments are significant and pervasive to speakers' vocational, social, economic, academic, emotional status. For example, individuals experience discrimination in obtaining housing, employment, or other basic needs; experience poor job performance evaluations and competence, poor customer service experience, patient safety and patient experience concerns with difficulty understanding the accents and communication of their physicans and other care providers, linguistic profiling and judgments of criminality in law based on accents, difficulty learning as students in classes with instructors with strong accents, to list a few reported issues (Baugh 2000; Segrest Purkiss et al. 2006; Deshields et al., 1996; Hill and Tombs, 2011; Jirwe et al., 2010; Kalin, 1982; Divi et al., 2007; Wyld, 2007; Dixon \& Mahoney, 2004). The implications and applications of listener bias have been studied and published on in many disciplines. There is a theoretical interest, such as in fields of sociology, psychology, linguistics. There is also an applied interest, such as applied fields dealing with communication related to customer service, sales, advertising and marketing, law and order, medical care provision, teaching and learning and so on (e.g., Baugh 2000; Segrest Purkiss et al. 2006; Deshields et al., 1996; Hills and Tombs, 2011; Lee, 1997). However, fields dealing with service providers helping people with their accents, e.g., SLP or ESL have not attempted to address or discuss the phenomenon of listener bias in the training and service provided to the people with accents. The available literature focuses mainly on helping the speakers improve their speech patterns (e.g., Shah, 2010 a) Shah, 2010 b; Shah, 2012 a; Behrman, 2014, 2017; Ojakangas 2013; Lam \& Tjaden, 2013), but there is not much information on helping speakers become aware of these biases (Burda, 2006; Ovalle \& Chakraborty, 
2013) or train them to manage these biases as part of the service provision (Shah, 2012b; Chakraborty, R., 2017). The inherent subjectivity in accent bias makes it difficult to interpret in a reliable manner, especially given the degree of bias varying across the personal bias of the listener, their experiences, and the context.

Given how prevalent accent bias is, it is important to acknowledge and better understand the qualitative aspects of listeners' interpretation of speakers' accent. For instance, why do listeners believe some accents are more intelligent than others, more trustworthy than others, richer or poorer than others and so on. From a clinical or teaching standpoint, there is much value in being able to understand listener experiences, what shapes them, and what are they challenged by as they listen to speakers with accents different from their own. The question also emerges whether the difficulty understanding the speakers is what causes negative biases in listeners, or whether the elements of the accents, or some other extrinsic, non-speaker related variables evoke the positive or negative biases. Understanding these nuances of the listener bias will help SLPs and ESL teachers become better equipped to teach, counsel, or coach their clients in accent interventions. Understanding the nuances of listener judgments will also help other applied fields, such as customer service, marketing, public relations and so on.

In light of the above context, the focus of this paper is on studying listener bias to clearly isolate what listeners are judging and what that source of judgment may have been borne out of. By controlling for inter-speaker differences, we present samples to listeners that are representative of the accent, but do not have the confounding variable that affect the judgment of listeners. In other words, if listeners were judging different accents across different speakers, they may have been judging some based on variables of voice, tone, English fluency, pitch, or quality of voice, instead of accent, per se. Hence we employed a matched guise technique of using the same speaker - an actor - and having her render all the accent recordings which were judged by native speakers as authentic samples and well-representative of each accent variety. Listeners thus received a sample that was thus better representative of the accent, and not other interfering factors. Additionally, we quantified and statistically tested the speaker attributes rated by the listeners, thus limiting the subjectivity in interpreting listener responses. Finally, we conducted meta-analysis of listeners' qualitative comments in listening to each accent sample. Further analysis of the comments helped identify patterns that decoded the underlying contributing sources of these biases. This paper demonstrates and discusses how both quantification and qualification of bias can help the service providers and service recipients.

\section{METHODOLOGY}

\section{Participants}

Listeners. 55 native English-speaking participants, ranging in age from 16 to 66 years served as Listeners. They were recruited through word-of-mouth advertising on campus and in the community. Participants were volunteers with general interest in the topic and received no compensation for participation. All of the participants were Caucasian. The participants were either Lorain County Community College (LCCC) or Lake Erie College (LEC) students, or LCCC instructors. Table 1 shows details of 44 respondents and 1848 observations. Of the 44 respondents, 21 respondents were men (47\%) and 23 respondents were women (53\%). One respondent did not report age. Because the mean age of the population is close to 34 , two different age categories were constructed. Respondents above 34 were placed in one category (44\%), and the remaining respondents were placed in the other category where ages of respondents either equal or are below $34(58 \%)$. The sample also varied by where respondents were born. Seven respondents did not report their place of birth. The majority of the respondents (30 out of 44) were born in Ohio, two were foreign-born (Germany and Vietnam) and the remaining were born in other parts of US. The Ohio-born majority is expected, as the respondents were volunteers from the local area where the study was conducted (Cleveland, Ohio). The divide between men and women with respect to age and place of birth are shown in Table 1. There were 17 females and 13 males out of 30 Ohio born respondents. There were similar number of men and women in the above 34 as well as 34 or under categories.

\section{Recording Procedure}

Seven accents were recorded and used as listening stimuli in this study: Brooklyn, Atlanta, London, Cleveland, Glasgow, Berlin, and Hispanic Tex-Mex, thus representing broadly diverse regional and foreign accented groups, namely, New York, Southern, English, Midwest, Scottish, German, and Hispanic respectively. These 7 accents were recorded by a single speaker who was a trained actor, following the matched guise technique (Lambert et al., 1960), to control for indexical differences across speakers, and see how listen-

Table 1. Descriptive statistics

\begin{tabular}{lc}
\hline Type of Characteristic & N \\
\hline Number of Respondents & 44 \\
Men & 21 \\
Women & 23 \\
Young (Less than or Equal to 34) & 25 \\
Old (Above 34) & 19 \\
Ohio Born & 30 \\
Foreign Born & 2 \\
Female Below 34 & 13 \\
Male Below 34 & 12 \\
Female Above 34 & 10 \\
Male Above 34 & 9 \\
Ohio Born Male & 13 \\
Ohio Born Female & 17 \\
Foreign Born Male & 1 \\
Foreign Born Female & 1 \\
\hline
\end{tabular}


ers judge the 7 varieties of accents itself. An authenticity test of the recordings was conducted using native speakers of the 7 accents and a trained speech-language pathologist to ensure that the recordings well-represented the accents of the respective regions, despite use of an actor, and not an actual native speaker. These details of recording and authenticity testing are reported in greater detail in a separate publication that focuses on the need to control indexical variables in measuring accent bias (Shah \& Chakraborty, 2019).

\section{Listening Procedure}

Participants (listeners) were presented the 7 recording samples and a survey form that asked them to include 1) demographic details such as their name (or use an alias), age, and where they were from; 2) rate the recording samples in terms of 6 attributes, namely, intelligence, friendliness, honesty, arrogance, socio-economic status, and pleasantness on a scale of one (low) to five (high); and 3) circle any of the following traits which might apply to the speaker, including: friendly, intelligent, warm, honest, respected, shrewd, arrogant, wealthy, attractive, and rigid. The survey form also included a space where participants could write a comment about the voice after each voice sample was heard. These qualitative comments were elicited to gain insights about listeners' stereotypes and attitudes.

\section{Data Analysis}

In this study 55 respondents were asked to evaluate six different attributes of seven accents. Ratings were done on a Likerttype scale (1-5, where $1=$ low and 5=high for each attribute, e.g., low intelligence versus high intelligence). The accents considered are New York, Southern, English, Midwest, Scottish, German and Hispanic. The attributes considered for each accent in this study are: Arrogance, Friendliness, Honesty, Intelligence, Pleasantness, and Socio-Economic Status (SES). The rating score on attributes of different accents is the main variable of analysis in this study.

\section{RESULTS}

\section{Results by Attributes}

Overall Means and Standard Deviations of Evaluation Scores across Accents by Each Attribute are shown in
Table 2. English, German and New York accents showed the highest mean ratings for the "arrogance" attribute. Midwest accent received the lowest rating in this category. Hispanic, Scottish, and Southern were also on the lower end of arrogance. For the attribute, "friendliness", the Southern accent sounded the most friendly followed by Scottish and Midwest. English, German and New York accents did not appear friendly. The responder perceptions of the accents for the attribute "honesty" were similar to friendliness. Southern, Scottish and Midwest accents were perceived to be most honest and German to be least honest. With regard to the attribute, "intelligence", English is perceived to be the most intelligent sounding accent and New York, Hispanic and Midwest are considered to be the least intelligent. Differences across accents for the attribute 'Pleasantness', mirrors the pattern of 'Friendliness'. Southern, Scottish and Midwest are perceived to be friendly and pleasant, while German, New York, English, and Hispanic appeared to be less friendly. With regard to SES, English, Southern and German accents reflected the highest SES, while Hispanic and New York accents were perceived as having low SES.

\section{Results of Overall Profile of each Accent by Attributes}

When the averages of different accents are graphed in Figure 1, the responder perceptions of each accent across different attributes become visible. Thus, the resulting "accent profiles" reveal the various attributes for each accent. The vertical axis measures the average scores on each attribute, while the horizontal axis measures the attributes. New York accent (demonstrated by a line connecting diamond shaped points on the graph) ranks higher in arrogance, lower in friendliness, lower in honesty, pleasantness, and friendliness, and lowest in intelligence and SES. English accent (demonstrated by a line connecting triangle shaped points on the graph) and German accent (demonstrated by a line connecting circle shaped points on the graph) have very similar profiles across different attributes. They are high on arrogance, low on friendliness, high on intelligence, low on pleasantness, and high on socio economic status. Southern accent (demonstrated by a line connecting square shaped points on the graph) and Scottish accent (demonstrated by a line connecting star shaped points on the graph) have dramatically opposite patterns compared to English and Ger-

Table 2. Overall means and standard deviations of evaluation scores across dialects by each attribute (based on 44 observations)

\begin{tabular}{|c|c|c|c|c|c|c|c|c|c|c|c|c|}
\hline \multirow[t]{2}{*}{ Dialect } & \multicolumn{2}{|c|}{ Arrogance } & \multicolumn{2}{|c|}{ Friendliness } & \multicolumn{2}{|c|}{ Honesty } & \multicolumn{2}{|c|}{ Intelligence } & \multicolumn{2}{|c|}{ Pleasantness } & \multicolumn{2}{|c|}{ SES } \\
\hline & Mean & sd & Mean & sd & Mean & sd & Mean & sd & Mean & sd & Mean & sd \\
\hline NY & 3.07 & 1.34 & 2.45 & 0.95 & 3.05 & 0.89 & 2.70 & 0.90 & 2.36 & 0.92 & 2.50 & 0.82 \\
\hline Southern & 2.75 & 1.37 & 4.16 & 0.75 & 3.59 & 0.97 & 3.09 & 0.91 & 4.07 & 0.97 & 3.48 & 0.98 \\
\hline English & 3.77 & 1.12 & 2.50 & 0.79 & 3.27 & 0.97 & 4.39 & 0.84 & 2.68 & 1.01 & 4.14 & 0.77 \\
\hline Midwest & 2.43 & 0.95 & 3.25 & 0.89 & 3.32 & 0.83 & 2.91 & 0.96 & 3.07 & 1.11 & 2.75 & 0.61 \\
\hline Scottish & 2.55 & 0.87 & 3.68 & 0.96 & 3.50 & 0.76 & 3.43 & 0.87 & 3.61 & 0.87 & 2.98 & 0.66 \\
\hline German & 3.55 & 1.17 & 2.23 & 0.83 & 2.66 & 0.83 & 3.48 & 1.11 & 2.09 & 0.96 & 3.50 & 0.93 \\
\hline Hispanic & 2.80 & 1.11 & 2.89 & 0.97 & 3.05 & 0.78 & 2.84 & 0.83 & 2.84 & 0.94 & 2.66 & 0.96 \\
\hline
\end{tabular}




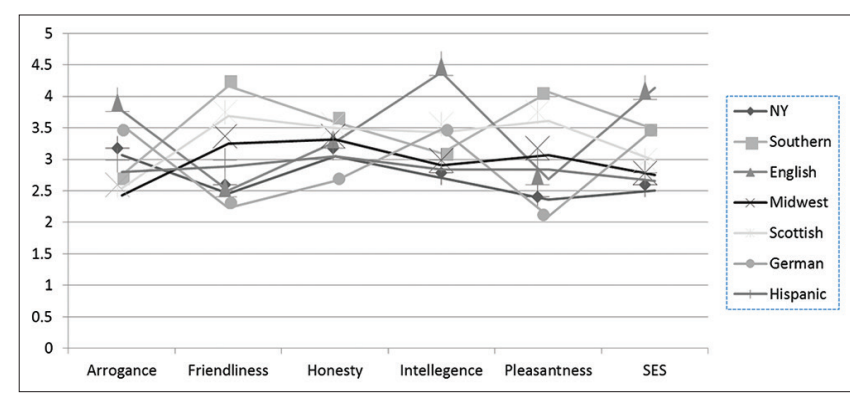

Figure 1. Overall profile of each dialect by attributes

man accents i.e. they are perceived to be low on arrogance, but high on Friendliness, Honesty and Pleasantness, medium on Intelligence and SES. Hispanic accent (demonstrated by a line connecting diamond bar points on the graph) displays low averages on each category, indicating that it is associated with lower intelligence, pleasantness, socioeconomic status, and medium in friendliness. Midwest accent (demonstrated by a line connecting cross shaped points on the graph) on every category lies somewhat in the middle of the other accents. This feature will be later exploited by computing the relative differences between the Midwest accent and comparing to the other accents for each attribute.

\section{Results of the Statistical Significance of Accent Attributes}

Unpaired t-tests were conducted to determine whether the difference between the average perception between different accents is statistically significant or not. Because a majority of respondents are born in Ohio and all of them are currently residing in Ohio, the Midwest accent was taken as the "norm" for the listeners, with which to compare the other accents. This may be why the Midwest accent has the middle-of-theroad averages in positive attributes like Friendliness or Pleasantness or Honesty and lowest ratings for negative attributes like Arrogance. It also had low standard deviations in each attribute, suggesting there is much agreement on the nature of Midwest accent. Therefore, the average of Midwest accent for every attribute can be considered as a norm from which differences of other accents will be computed and tested for statistical significance. A statistically significant difference may form the basis of bias in perception. Additional details on this novel methodology to quantify listener bias using comparative norms can be found in Shah (2019).

Figure 2 presents the differences of average score of an accent in a specific attribute to the Midwestern average score for that attribute. The vertical axis shows the differences between the average of any accent and the Midwest accent, while the horizontal axis shows the different accents. For any attribute, the difference of the average score on Midwest accent to itself is 0 and would be indicated by a point on the horizontal line corresponding to 0 on the vertical axis. For the Arrogance attribute, all the other accents were rated above the average Midwest accent score. This is reflected through the vertical lines on all accents going upward from 0 . English accent and German accent are the most different from the Midwest accent in Arrogance. The corresponding unpaired t-tests show that the difference of the score of Arrogance for Midwest is statistically significantly different from New York, English, and German accents. The same graph for difference in Friendliness scores from the Midwest accent reveals that while New York, English, German, and Hispanic accents were considered less friendly than the Midwest accent, Southern and Scottish accents were considered friendlier. The t-test tables for Friendliness confirm that the differences of all (except Hispanic) accents from the Midwest accent score is statistically significant. For the Honesty attribute, the mean score on only German accent was significantly different from the Midwestern accent. The mean scores on the remaining accents were not statistically different from the score on the Midwest accent for Honesty. In the case of Intelligence, the mean scores of English, Scottish and German were found to be significantly higher than the score on Midwest. However, New York and Hispanic accent mean scores were lower than that of Midwest but the difference was found to be statistically insignificant. All but English and Hispanic accents were found to be statistically different from the Midwest accent on the attribute of Pleasantness. Finally, Southern, English, and German were statistically different from the Midwest accent on the attribute of SES.

\section{Results of the Qualitative Analysis of Listener Comments}

Listeners were asked to write descriptive comments about the speech, if they chose to, after each speech sample was heard. These qualitative comments provide direct insight into what parameters or reference points the listeners were evaluating the sample on basis of, and, in turn, reveal the underlying basis to their stereotypes and attitudes. This qualitative information also provides a validity cross-check for the quantitative data above, as well as providing novel information that help understand the patterns across the quantitative scores. The following is a summary of the findings by accent (See Appendix A for direct quotes and complete list of comments).

1. New York accent. Most listeners typically identified this accent to be a "Brooklyn" accent, and in particular, of the Brooklyn Italian type. A general dislike of New Yorkers was expressed in the comments as the accent was typically associated with references to Italian mafia and thugs. The accent was perceived to be rich (higher SES) because of the mafia association, as evident from the comments. Certain characteristics associated with the accent included: streetsmart, pushy, rude, snotty, and unattractive. The comments suggest that it was not the speech or voice quality, per se, that elicited these negative associations - given that it was the same speaker/voice across all the accent samples--but rather their preconceived stereotypes of what Brooklyn New Yorkers are like, either from their personal experiences, or driven by media-based images.

2. Southern accent. A bimodal pattern emerged in the perception of the Southern accent. One set of opinions made a positive association where the accent appeared "relaxed", "calm", "friendly" and "nice to listen 


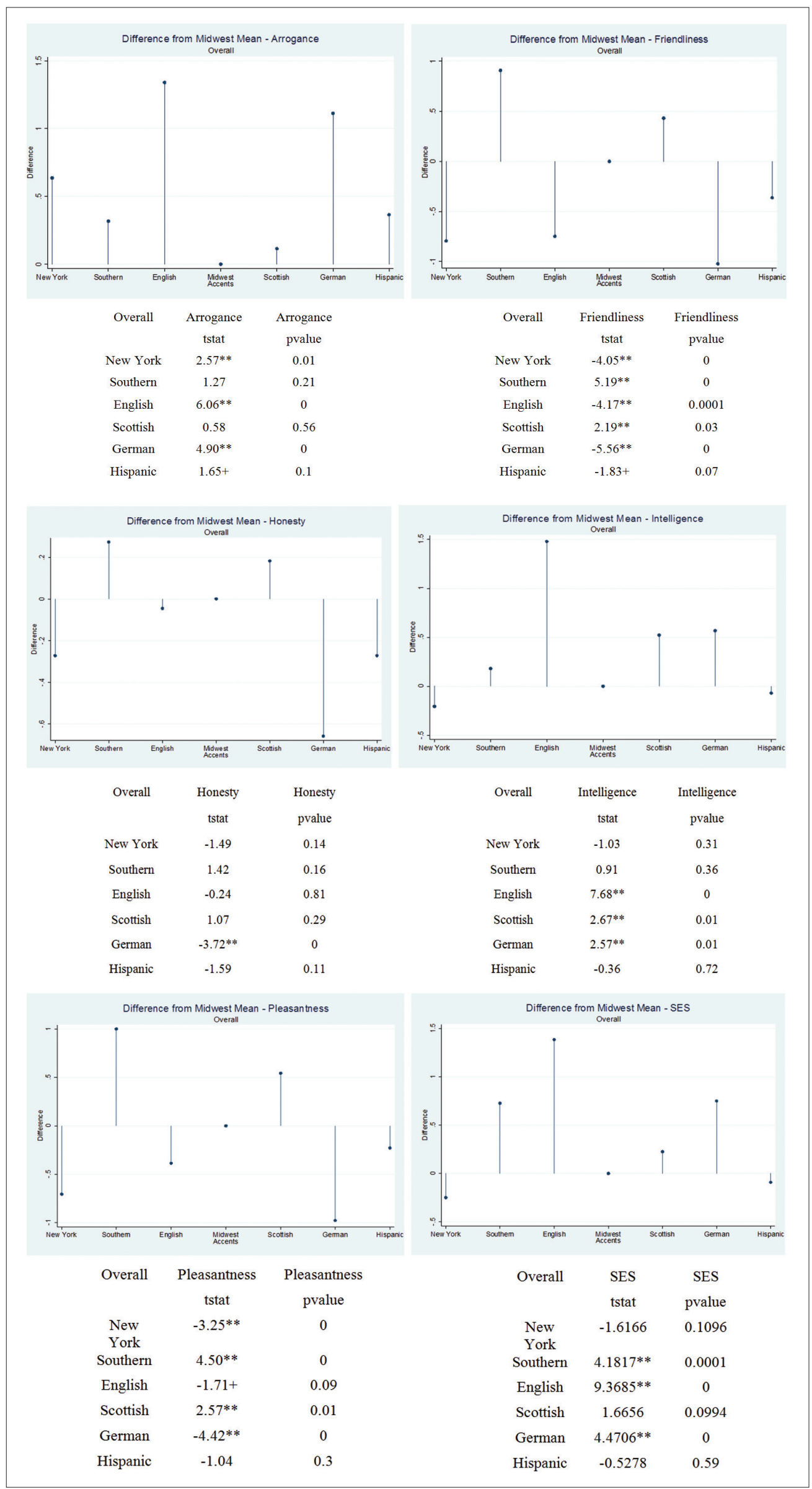

Figure 2. Relative strength of dialect perception (compared to Midwest standard) by attribute and statistical significance 
to". An opposing set of views identified the accent as "full of self", "rich Southern Belle", "liar," "blonde fluffy", "religious", "not intelligent", and "slow mental processing".

3. British accent: The accent was typically associated with media references to BBC/NPR, thereby the higher SES Received Pronunciation rather than a working class variety. The more prevalent characteristics associated were: "sophisticated", "high SES", "uppity", and "haughty".

4. Midwestern accent: The prevalent response to this accent was "normal", or "ordinary, "not unusual, regular." Participants also typically conveyed a positive association for the accent: "sounds like an average, down to earth friendly person", and "very pleasant". There were a few negative comments expressed: "bland", "brittle", "annoying", and "nasal"

5. Scottish accent: Many of the Northeastern Ohio-born participants were confused as to whether the voice was Scottish or Irish. One person found the voice "annoying in intonation", but most responses were favorable, including "enjoyable", "averagely nice", "cool voice", "fantasticle" [sic], and expressed preferences for listening to it. Two responses provided additional attributes on the perceived nature of the speaker: "usually poor but nice, friendly, maybe a little stubborn", and "Scottish people are penny-pinchers". Gender perceptions of the speaker were interestingly mixed, with one person responding with "nice Irish lady", another with "sounds like my Grandmother", one "Irish lad" and one "Scottish laddie", as well as references to "Pippin from Lord of the Rings" and "Willie the Groundskeeper" (a Scottish character on The Simpsons).

6. German accent: There was some confusion regarding this accent's origin. Some people perceived it as being "Russian", "Slovak, Czech", or possibly Austrian, with a reference to media personality, Arnold Schwarzenegger ("my name is Arnold. I am here to pump you up.") or Transylvanian (I vant to suck yr [sic] blood!"), however most seemed to perceive that it was German. The overwhelming response to this accent was negative. There were two positive responses: "good" and "Slovak, Czech, friendly, thankful, maybe German", two that seemed neutral, "sounds like a German lady" and "sounds rigid but is not necessarily so", and many that were less than flattering: "not trustworthy," "I don't like this voice; it makes me feel uncomfortable," "cold", "feared", "strong, harsh", "sounds picky," and "lispy". Several male participants made associations with spy references ("Russian or German spy", "kiniving [sic] German spy women [sic].

7. Hispanic accent: Some remarked on its origin: "Latino", "sounded New Yorkish. I'm not keen on NYers...", "Puerto Ricaño", "Mexican-- nice", "Sounds Indian or Arabic, I don't know", "Latina from the hood," "Sounds like a Latino woman," and "¡Viva Puerto Rico!" Others remarked on its qualities: "wonderful", "dull", "indistinctively rigid?". Still others remarked on the perceived qualities of the speaker: "sounds like she could mess you up", "street smart, maybe slutty", "kind of dumb sounding" and "rich wife". One person equated the accent with the voice of "Speedy Gonzales".

\section{General Themes from the Qualitative Comments: What is Novel that Adds Scientific Value?}

1) People can recognize/identify accents without being told; this accent recognition appears consistent across a group of people from the same region, and the identification of the region of the accent is largely accurate

2) Misperceptions regarding the region of the accent showed that there were some confusions between NYC (Manhattan) versus Brooklyn accents, Scottish versus Irish, Spanish versus Arabic, and German versus several East European languages. Occasionally, gender confusions were noted in the case of the Scottish accent where the speech sample could not be consistently identified as male or female.

3) Having controlled for inter-speaker differences of indexical features by using the same speaker for all accents, it then appears that listeners are not reacting to specific vocal/indexical attributes (E.g., loudness, pitch, resonance, speaking rate, or quality of the voice samples), but rather have their preconceived references of characteristics associated with the region of origin of the accent. Thus, it appears that people are reference-oriented.

4) These underlying reference points are typically borne out of the influence of media, TV, and movies. Besides character traits, the listeners also frequently inferred occupations/professions from the accents, e.g., New York= mafia or thugs; British=Media personality or Professor; German= spy

5) Accent judgments are not reserved for foreign accents alone; regional accents are also subject to judgments and stereotypes.

6) While anecdotally it is held that negative reactions to accents are typically borne out the reduced intelligibility/clarity of the accent, causing listeners to struggle to understand the speaker, this study demonstrates the opposite. Despite all the accent samples being intelligible, all of them were subject to various positive or negative judgments, that varied by listeners' own accent, gender, personal or social experiences, and messages received from mainstream media. This last point is especially crucial for speech clinicians and ESL teachers who provide accent modification to become aware of challenges related to accents, even when that accent is intelligible. Clinicians and teachers can design their communication instruction to address these psychosocial barriers and not just focus on intelligibility goals. Similarly, administrators, and policy makers can benefit from these findings by learning that a lack of intelligibility is not the only hindrance in the way of effective intercultural communication; this awareness can be of help as they plan training and programs for effective cross-cultural communication, cultural competence training, and diversity education for professionals and employees. 


\section{DISCUSSION}

While previous literature has clearly shown that stereotypes and bias (both positive and negative) exists towards accents, the nuances of listeners' judgments and the underlying bases of these judgments were not well-established in the previous literature. As reported in another paper detailing the quantification method (Shah, 2019), we assert that quantification allows a more objective and reliable interpretation of perceptual bias which tends to be an inherently subjective, and thereby unreliable phenomenon. To quantify and understand the patterns of perceptual bias towards accents, the bias of perception is measured by the difference between the average scores of a non-standard accent on an attribute from that of the listeners' own accents. Further, this difference is tested for statistical significance. Means for each attribute showed that English, German and New York accents received the highest mean ratings for the "arrogance" attribute. Midwest accent received the lowest rating in this category. Hispanic, Scottish, and Southern were also on the lower end of arrogance. For the attribute, "friendliness", the Southern accent was rated the highest, followed by Scottish and Midwest. English, German and New York accents were rated low on friendliness, i.e., they did not appear friendly to the listeners. The attribute "honesty" was rated similar to friendliness in that the Southern, Scottish and Midwest accents were perceived to be most honest and German to be least honest. With regard to the attribute, "intelligence", English was perceived to be the most intelligent sounding accent and New York, Hispanic and Midwest were considered to be the least intelligent. Differences across accents for the attribute 'Pleasantness', mirrors the pattern of 'Friendliness'. Southern, Scottish and Midwest are perceived to be friendly and pleasant, while German, New York, English, and Hispanic appeared to be less friendly. With regard to SES, English, Southern and German accents reflected the highest SES, while Hispanic and New York accents were perceived as having low SES. These findings were largely statically significant: New York, English and German were significant on Arrogance; all but the Hispanic accent were statistically significant on Friendliness; only German accent was statistically significant for Honesty; English, Scottish, and German were significantly significant for Intelligence; all but the English and Hispanic accents were statistically significant for Pleasantness; and Southern, English, and German were statistically significant for SES. Taken together, the consistency of patterns across listeners and the statistical significance of these patterns suggest that the perceptual notions held for each of these seven accents are not subjective nor random. This finding adds to previous literature on stereotypes held for accents, and further confirms the strength of these notions through this quantifying approach. Furthermore, the stereotypes and beliefs about each accent can be seen as firmly rooted since they hold up even in simulated situations, such as the matched guise method used in this study.

In fact, the stereotypes hold up well enough to construct accent profiles for each accent, as reported in Shah (2019). For example, New York accent is perceived as being higher in Arrogance, lower in Friendliness, Honesty, and Pleasantness, and lowest in Intelligence and SES. The English and German accents have very similar profiles across different attributes. They are high on Arrogance, Intelligence, and SES; and low on Friendliness and Pleasantness. The Southern and Scottish accents have dramatically opposite patterns compared to English and German accents i.e. they are perceived to be low on Arrogance, but high on Friendliness, Honesty and Pleasantness, and medium on Intelligence and SES. Hispanic accent displays low averages on each category, indicating that it is associated with lower Intelligence, Pleasantness, Socioeconomic Status, and medium in Friendliness. Not surprisingly, the Midwest accent lies somewhat in the middle of the other accents in every category. Given that the listeners were mostly from the Midwest, their own accent appears to have served as a "norm" or "standard" variety against which other accents were compared.

After confirming that these stereotypes are consistently upheld, the important question arises-which is the central question and focus of the present paper-as to what might be contributing sources of these stereotypes-in other words, why do listeners believe what they do, and judge the way they do? The qualitative comments sought from the listeners provide useful information to these questions, and give an insight into what the listeners are thinking as they listen to these accents. It was clear that the listeners felt uncensored to comment given the detailed comments they provided as well as their lack of attempting to be only positive or polite. Qualitative comments distinguish that the bases of these comments appear to be derived from media references: English accent associated with the exposure to the BBC or NPR media experiences, and German accent to the associations with world war and spies. The perceptions for the New York accent appear to be borne out of the reference associations being made with the interpretation that it is a Brooklyn, Italian, working-class accent (rather than a rich, well-educated, white-collar, Wall Street variety). Thereby the listeners appear to relate this accent variety to the personality stereotypes portrayed in media (e.g., mafia or action movies) such as the Godfather, Rocky, and so on). While Scottish was generally regarded favorably, the Southern accent instead drew out two opposing perceptions with some listeners enjoying listening to it and others disliking it. The negative connotations held for the Hispanic accent appear to rise from the fact that it is associated with a working-class, low-educated variety.

To our knowledge, this is also the only study to ask responders to provide qualitative responses (e.g., type of accent, in addition to the quantitative ratings on attributes of accents). The accent type was not revealed by the experimenter to the responders. These qualitative statements show if the responders correctly identify the accents presented to them. The qualitative comments also help provide a validity check for the quantitative ratings, by observing how well the quantitative data on different accents is correlated to the responder comments.

\section{Theoretical and Clinical Implications of the Findings}

From a theoretical perspective, findings from this study indicate that bias for and against accents appears to be more of a 
preconceived notion on part of cultural group, established by influences and messages from the media and popular culture. This assessment by cultural groups reserved for each accent appears to be applied even to speakers who are actually not from that culture or region (e.g., the actor in this study), as long as they appear to have stereotypical features of that accent. This finding has clinical relevance as well implication for sociology theories. Clinically, findings from this study provide important and new information to Speech-language pathologists (SLPs) as they provide accent-modification services. Typically, SLPs are trained to provide accent-modification to clients for intelligibility challenges related to their unique speech patterns, accents, and communication diversity (ASHA, 1998). However, findings of this study suggest that listeners' preconceived biases may continue to emerge due to the entrenched, fixed stereotypes held for any given accent, regardless of how intelligible or fluent a speaker may eventually become. In that sense, listeners are not making their decisions based on the speaker, per se, as much as they are for their held assumptions and preconceived stereotypes for that accent in general, regardless of the speaker. The consistency or patterns of bias across listeners and statistically significant strength of findings further make a compelling case to acknowledge that accent bias is a real and impactful issue, worthy of considering in accent management and accent intervention (or what is popularly known as "accent modification"). Findings from the present paper can contribute to such discussions by bringing useful awareness to SLPs about the nature of bias, the psychosocial environment and judgments that their diverse clients face due to their accents, and perhaps even become aware of their own biases (e.g., Perry, Murphy, \& Dovidio, 2015). Indeed, as asserted by Chakraborty (2017), "the field of Speech Language Pathology has offered a cursory attention to the issue of accent related biases"... and that "it is critical to engage in formal discussion on accent discrimination".

Furthermore, speaking with an accent can often be confused or confounded with being limited in speaking proficiency of English. The literature review in this present paper has demonstrated that both, accents as well as limited English proficiency have wide-ranging consequences in a variety of professions. By using the same proficient speaker of English across all the recorded samples, the present study was able to confirm that listeners held prejudice and preferences for differing varieties of accents, per se, even when they are free of language proficiency issues. This finding bears implications for clinicians working with accent modification as it shows that individuals are likely to experience communication barriers and buy-in from listeners even when their accent is completely intelligible. Thus, accent modification will need to consider other goals and outcomes that go beyond establishing speech intelligibility as is currently done and advocated (ASHA, 1998).

Findings from this study have implications for theories of social identity and ethnocentricicm (e.g., Hogg, 2004; Tajfel, 1972). Listener judgments of accents and attributes in this study conformed with the predictions from a theory of ethnocentricism in the way listeners created in-group identification (rating fellow midwesteners more neutrally) and outgroup derogation and discrimination (e.g., rating poorly on attributes of intelligence, trustworthiness, and friendliness for accents that were markedly different from their own). However, existing theories of social identity and ethnocentricism do not explain the findings here of why some outgroups received negative ratings and others received positive ones; the influence of media and cultural buy-in to some of the propaganda is still unclear and worthy of further study.

In conclusion, the focus of this paper was on studying listener bias to clearly isolate what listeners are judging and what that source of judgment may have been borne out of. Previous literature has not attempted to help clinicians and trainers become aware or their own biases or train them to manage these biases as part of the accent services and interventions. The results and findings of this paper-especially the detailed insights gained from analyzing listeners' subjective-and yet consistent bias patterns-is a direct effort to help clinicians and trainers in the realm of accent interventions become aware of some of the internal dialog of listeners and thereby, seek to address and empower their accent clients. The study presented in this paper helped understand some of the patterns underlying preferences and biases as listeners rate and judge accents. Our next step in this research is to conduct acoustic analyses of the accent samples to understand how they correlate to the accent perceptions to further our understanding of the underlying substrates of speech that drive perception in a continued effort towards improving accent interventions.

\section{REFERENCES}

ASHA Joint Subcommittee of the Executive Board on English Language Proficiency. (1998).Students and Professionals Who Speak English with Accents and Nonstandard Accents: Issues and Recommendations (No. TR1998-00154). Rockville, MD: American Speech-Language-Hearing Association. Retrieved from http://www. asha.org/policy/TR1998-00154/

Baugh, J. (2000). Racial Identification by Speech. American Speech, 75(4), 362-364. doi:10.1215/0003128375-4-362

Behrman, A. (2014). Segmental and Prosodic Approaches to Accent Management. American Journal of Speech-Language Pathology, 23 (4), 546-561.

Burda, Riess, A. (2006). Perception of Accented Speech: A Summary of the Research. Perspectives on Gerontology, 11(1), 3-7

Chakraborty, R. (2017). A short note on accent-bias, social identity, and ethnocentricicm. Advances in Language and Literacy Studies, 57-64. Retrieved from http:// www.journals.aiac.org.au/index.php/alls/article/viewFile/3703/2979

DeShields Jr., O. W., Kara, A., \& Kaynak, E. (1996). Source effects in purchase decisions: The impact of physical attractiveness and accent of salesperson.International Journal of Research in Marketing, 13(1), 89-101. doi:10.1016/0167-8116(95)00036-4 
Divi, C., Koss, R.G., Schmaltz, S. P. \& Loeb, J. M. (2007). Language proficiency and adverse events in US hospitals: a pilot study. International Journal of Quality Health Care, 19 (2), 60-67.

Dixon, John A., \& Mahoney, B. (2004). The effect of accent evaluation and evidence on a suspect's perceived guilt and criminality. The Journal of Social Psychology, 144(1), 63-73. doi:10.3200/SOCP.144.1.63-73

Giles, H., \& Coupland, N. (1991). Language: Contexts and Consequences. Open University Press.

Hill, S. R., \& Tombs, A. (2011). The effect of accent of service employee on customer service evaluation. Managing Service Quality, 21(6), 649-666. doi:10.1108/09604521111185637

Hogg, M. A., Abrams, D., Otten, S., \& Hinkle, S. (2004). The social identity perspective intergroup relations, self-conception, and small groups. Small group research, 35(3), 246-276

Jirwe, M., Gerrish, K., \& Emami, A. (2010). Student nurses' experiences of communication in cross-cultural care encounters. Scandinavian Journal of Caring Sciences, 24(3), 436-444. doi:10.1111/j.14716712.2009.00733.x

Kalin, R. (1982). The social significance of speech in medical, legal, and occupational settings. In Attitudes towards language variation: Social and applied contexts (pp. 48-63). London, England: Edward Arnold.

Kenney, C., \& Shah, A. P. (2011). Accent Perceptions \& Stereotypes: Why should you care? Seminar presented at the National convention of the American Speech, Language, and Hearing Association, San Diego, CA. Retrieved fromfile://C:/Users/2414701/Downloads/Kenney-Shah\%20(1).pdf

Lam, J. and Tjeden, K. (2013). Intelligibility of Clear Speech: Effect of Instruction. Journal of Speech, Language, and Hearing Research, 56 (5), 1429-1440.

Lambert, W. E., Hodgson, R. C., Gardner, R. C., \& Fillenbaum, S. (1960). Evaluational reactions to spoken languages. The Journal of Abnormal and Social Psychology, 60(1), 44-51. doi:10.1037/h0044430

Lee, J. J., \& Rice, C. (2007). Welcome to America? International student perceptions of discrimination. Higher Education, 53(3), 381-409. doi:10.1007/s10734-0054508-3

Mestre, M. V., Samper, P., Frías, M. D., \& Tur, A. M. (2009). Are Women More Empathetic than Men? A Longitudinal Study in Adolescence. The Spanish Journal of Psychology, 12(01), 76-83. doi:10.1017/S1138741600001499

Ojakangas, C. L. (2013). Viewpoint: What Brain Research Can Tell Us About Accent Modification, Perspectives on Communication Disorders and Sciences in Culturally and Linguistically Diverse (CLD) Populations, 20 (3), 101-108.
Ovalle, B. and Chakraborty, R. (2013). Accent Policy and Accent Modification Enterprises as Potential Indicators of Intercultural Power Relations: A Call for an Updated Research Agenda. Perspectives on Global Issues in Communication Sciences and Related Disorders, 3 (1), 22-33.

Perry, S. P., Murphy, M. C., \& Dovidio, J. F. (2015). Modern prejudice: Subtle, but unconscious? The role of Bias Awareness in Whites' perceptions of personal and others' biases. Journal of Experimental Social Psychology, 61, 64-78. DOI: 10.1016/j.jesp.2015.06.007

Romaine, S. (2008). Variation in Language and Gender. In J. Holmes \& M. Meyerhoff (Eds.), The Handbook of Language and Gender (Vol. 98). Oxford, UK: Blackwell Publishing Ltd. Retrieved fromhttp://people.cohums. ohio-state.edu/schwenter1/Romaine\%202003.pdf

Shah, A. P. (2010 a). An International Medical Doctor in Practice: A Representative Case Study of a High English Proficiency Client for Accent Modification. In $S$. Chabon \& E. Cohn (Eds.), "Communication Disorders: A Case-Based Approach: Stories from the Front Line", Ch. 46, 393-402, Allyn \& Bacon.

Shah, A. P. (2010 b). An International Student on Campus: A Representative Case Study of a Low English proficiency Client for Accent Modification. In S. Chabon \& E. Cohn (Eds.), "Communication Disorders: A CaseBased Approach: Stories from the Front Line”, Ch. 47, 403-409, Allyn \& Bacon.

Shah, A. P. (2012 a). Accent Modification for Speakers With Indian Accents: Speech Characteristics and an Assessment Framework. Perspectives on Communication Disorders and Sciences in Culturally and Linguistically Diverse (CLD) Populations, 19 (1), 12-20

Shah, A. P. (2012 b). Know the costs but appreciate the values of accents. ASHA Leader, http://www.asha.org/Publications/leader/2012/120313/Helping-Clients-Choosea-Voice.htm

Shah, A. P. (2019). A Quantification Approach Towards Understanding Accent Bias (forthcoming).

Shah, A.P. \& Chakraborty, A. (2019). An Experimental Paradigm to Assess Accent bias associated with seven regional and foreign varieties (forthcoming).

Segrest Purkiss, S. L., Perrewé, P. L., Gillespie, T. L., Mayes, B. T., \& Ferris, G. R. (2006). Implicit sources of bias in employment interview judgments and decisions. Organizational Behavior and Human Decision Processes, 101(2), 152-167. doi:10.1016/j.obhdp.2006.06.005

Tajfel, H. (1972). La catégorisation sociale [Social categorization]. In S. Moscovici (Ed.). Introduction à la psychologie sociale (Vol. 1, pp. 272-302). Paris: Larousse.

Wyld, D. C. (1997). Accent Discrimination: Implications for the Multicultural Educational Institution of the $21^{\text {st }}$ Century. CUPA Journal, 47, 21-26. 


\section{Appendix A: Qualitative Comments by Responders}

1) New York

\begin{tabular}{ll}
\hline Men & Women \\
\hline "Don't like the voice" & "Pretty average" \\
"Reminds me of Boston Rob from Survivor" & "Sounded like she was from NY" \\
"Sounds like a New Yorker" & "Nasality noticeable" \\
"Yo! Adrian!" & "NY, NY" \\
"NY. I hate New Yorkers" & "rude NY Italian, maybe Brooklyn" \\
"Blah-ish" & "snore.boring, dull, dull, deadly dull" \\
"NY" & "street smart" \\
NY voice" & "Sounds like a subdued Andrew Dice Clay" \\
"Snotty New Yorker" & "NY voice" \\
"They wouldn’t be a friend of mine" & "didn’t like to listen to it" \\
& "sounds like my uncle" \\
& "well-respected in their own circle, tough" \\
& "could be in mafia; SES could be high due to illegal activity" \\
& "Sounded like a New Yorker" \\
\end{tabular}

2) Southern

\begin{tabular}{ll}
\hline Men & Women \\
\hline "Georgia?" & "Southern Belle type" \\
"Southern" & "unique?" \\
"very nice to listen to" & "rich Southern Belle slut liar" \\
"Southerners bleh" & "very nice to listen to, soothing" \\
"relaxed, calm" & "I wouldn't trust anything a Southern Belle said to me" \\
"full of self" & "sounds like an average housewife" \\
"sounds like a rich southern girl" & "Southern Belle" \\
"Southern" & "Southern" \\
"hate Southern accents" & "eek.blonde and fluffy with face paint" \\
& "southerners make me flinch when are they going to say \\
& praise the lord" \\
& Southern belle \\
& Not intelligent \\
& Slow mental processing \\
& Sounds as though they are from the south \\
& People from the south are friendlier \\
\hline
\end{tabular}


3) English

\begin{tabular}{ll}
\hline Men & Women \\
\hline Reminds me of someone with a lot of money & Snotty smart stuffy \\
Sounds snooty & British I know good friends \\
Sounds british & British/bbc voice \\
Sophisticated & British quality all on its own \\
Snotty to the nth power & NPR foreign correspondent \\
The bbc radio correspondent from npr & Englishman \\
& Uppity \\
& Very hotty \\
& Sounds like a history professor \\
& James bond gone bad \\
\hline
\end{tabular}

\section{4) Midwestern}

\begin{tabular}{ll}
\hline Men & Women \\
\hline Normal & Just an average young girl \\
Midwestern & Eh \\
Annoying & Nasally person annoying \\
Nasal & Needs help \\
Callow & Normal \\
Sounds like an average down to earth friendly person & Normal \\
No emotional response & Bland \\
Annoying & Brittle \\
Sounds normal & Ordinary not unusual regular \\
Very pleasant & Familiar \\
\hline
\end{tabular}

\section{5) Scottish}

\begin{tabular}{ll}
\hline Men & Women \\
\hline Scottish people are penny pinchers & Irish \\
Scottish - sounds like pippin from lord of the rings & Fantastical \\
Scottish & Enjoyable nice Irish lady \\
- averagely nice nothing bad or special & Annoying and intonational \\
Scotland & Cool voice I love Irish and Scottish \\
Scottish & sounding voices \\
Irish & I love that voice \\
Go fighting Irish & I love Scottish accents \\
& Irish person \\
& Irish lad \\
& Ooh ooh say wanker say toilet \\
& Scottish laddie \\
& Willie the grounds keeper \\
& Sounds like my grandmother \\
\hline
\end{tabular}


6) German

\begin{tabular}{ll}
\hline Men & Women \\
\hline Not trustworthy & Slovak Czech friendly thankful maybe German \\
I just do not like this voice it makes me feel uncomfortable & Germans strong \\
Russian & Sounds rigid but it is not necessarily so \\
Sounds like a German lady & Sounds like the guy from Hoyne's hero that fat evil \\
& nazi guy \\
Cold & Ve meet again de jones \\
I want to suck your blood & My annoying old English teacher \\
Conniving German spy woman! Ah! & Sounds picky \\
German & Lispy \\
Russian or German spy & Good \\
Feud & German Nazi type \\
My name is Arnold I am here to pump you up & \\
\hline
\end{tabular}

\section{7) Hispanic}

\begin{tabular}{ll}
\hline Men & Women \\
\hline Street smart may be slutty & Latino \\
Latinos from the hood & Wonderful \\
Kind of dumb sounding & Doll \\
Sounds like a Latino women & Speedy Gonzales \\
Rich wife & Sounds like she could mess you up \\
Viva Puerto Rico! & I am afraid accent sounded New Yorkish I am not keen on New Yorkers \\
& Puerto Ricano \\
& Indistinctively rigid \\
& Mexican- nice \\
& Sounds Indian or Arabic \\
\hline
\end{tabular}

